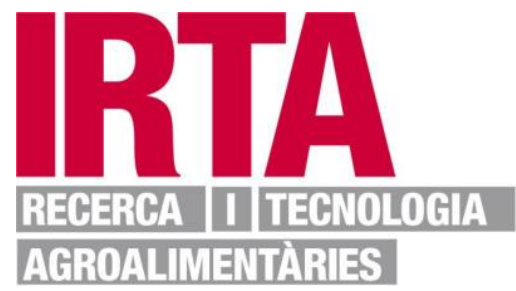

This is a post-peer-review, pre-copyedit version of an article published in Food and Bioprocess Technology. The final authenticated version is available online at: https://doi.org/10.1007/s11947-018-2191-5. 


\section{Effect of thermosonication on the bioaccessibility of antioxidant}

2 compounds and the microbiological, physicochemical, and nutritional

3 quality of an anthocyanin-enriched tomato juice

4 Tomas Lafarga a , Isabel Ruiz-Aguirre ${ }^{\text {b }}$, Maribel Abadias ${ }^{\text {a }}$, Inmaculada Viñas ${ }^{\text {b }}$, Gloria

5 Bobo ${ }^{\text {a }}$, and Ingrid Aguiló-Aguayo ${ }^{\text {a* }}$

6 a IRTA, XaRTA-Postharvest, Parc Científic i Tecnològic Agroalimentari de Lleida, Parc

7 de Gardeny, Edifici Fruitcentre, 25003, Lleida, Catalonia, Spain.

$8 \quad{ }^{\mathrm{b}}$ Food Technology Department, University of Lleida, XaRTA-Postharvest, Agrotecnio

9 Center, Lleida, Spain.

10

11 *Corresponding author:

12 Dr Aguiló-Aguayo: phone: (+34) 973003431 Ext. 1551, email: Ingrid.Aguilo@ irta.cat

16 Abbreviations

17 PG: polygalacturonase; PME: pectin methylesterase; TPC: total phenolic content; TAC: 18 total anthocyanin content; TLC: total lycopene content; SSC: soluble solids content; CJ:

19 control tomato juice; TAM: Total aerobic mesophilic microorganisms; AEJ: anthocyanin20 enriched juice; P-AEJ: Thermally treated anthocyanin-enriched tomato juice; TS-AEJ: 21 Thermosonicated juice; TTA: titratable acidity; $C^{*}{ }_{a b}$ : Chroma; $\delta E$ : Difference from the 22 control; DPPH: 2,2-diphenyl-1-picrylhydrazyl; FRAP: Ferric ion reducing antioxidant 23 power; SPC: Strawberry press cake; S.D.: Standard deviation; ANOVA: Analysis of 24 variance. 


\section{Abstract}

26 The aim of this study was to assess the potential of thermosonication as a strategy to

27 obtain safe and high quality tomato juice enriched in anthocyanins, formulated using

28 strawberry processing co-products. Incorporation of strawberry press cake into the tomato

29 juice resulted in higher polyphenolic and anthocyanin content and increased antioxidant

30 capacity. Thermosonication for $5 \mathrm{~min}$ at $60^{\circ} \mathrm{C}$ at either 35 or $130 \mathrm{kHz}$ resulted in higher

31 microbial inactivation when compared to thermal pasteurization at $80{ }^{\circ} \mathrm{C}$ for $1 \mathrm{~min}$. In

32 addition, thermosonication allowed increased retention of colour attributes as well as

33 polyphenol, lycopene, anthocyanin, and antioxidant capacity retention when compared to

34 thermal treatment. For example, the total anthocyanin content decreased from $1.08 \pm 0.04$

$35 \mathrm{mg} / 100 \mathrm{~mL}$ before processing to $0.92 \pm 0.01 \mathrm{mg} / 100 \mathrm{~mL}$ after thermal pasteurization but

36 the difference was not significant when compared with the thermosonicated juice (1.06 \pm

$370.03 \mathrm{mg} / 100 \mathrm{~mL})$. Although bioaccessibility of phenolic compounds after a simulated

38 gastrointestinal digestion was lower in processed juices, thermosonicated samples

39 showed a higher bioaccessibility when compared to the thermally-treated ones.

41 Keywords: tomato juice, anthocyanins, thermosonication, pasteurization, co-product 42 revalorisation, functional foods 


\section{Introduction}

44 Anthocyanins, which belong to the flavonoids subclass of polyphenols, are naturally occurring pigments which are responsible for the orange, red, violet, or blue colours of fruits and vegetables (Manach et al. 2004). Because of their peculiar chemical structure, anthocyanins can react with reactive oxygen species and present high antioxidant properties (Bueno et al. 2012). In addition, ingestion of anthocyanins and anthocyaninrich foods has been associated with a lower risk of suffering from hypertension (Cassidy et al. 2010) and type-2 diabetes (Muraki et al. 2013). Because of their health-promoting benefits, previous studies developed foods fortified in anthocyanins. For example, Sui et al. (2016) developed a functional bread enriched in anthocyanin-rich black rice bran powder, which showed a lower digestion rate and extra health benefits. Similarly, Gültekin-Özgüven et al. (2016) developed a chocolate fortified with encapsulated anthocyanins.

Strawberries (Fragaria $\times$ ananassa) are naturally rich in anthocyanins and other phytochemicals such as phenolic acids. Because of their high content in health-promoting phytochemicals and high antioxidant activity, co-products generated during strawberry processing such as strawberry press cake or strawberry pomace are promising ingredients

60 for food applications (Šaponjac et al. 2015). Their use as new food ingredients could open novel commercial opportunities, reduce the amount of food discarded as waste or used for low value purposes, and increase the consumption of anthocyanins and therefore

63 promote health. However, anthocyanins show instability towards a variety of chemicals

64 and physical parameters including $\mathrm{pH}$ variations, high temperatures, and light (Fernandes

65 et al. 2018). In addition, the structure and composition of the food matrix may either enhance or prevent the release and solubilisation of anthocyanins during digestion and

67 hence their bioaccessibility and bioavailability (Pineda-Vadillo et al. 2017). 
Microorganisms and enzymes including polygalacturonase (PG; EC 3.2.1.15) and pectin methylesterase (PME; EC 3.1.1.11) are involved in the deteriorating modifications of fruit and fruit-based products that can cause colour, flavour, or nutritional changes. Inactivation of microorganisms and enzymes is achieved in the food industry mainly by heat treatments (Jabbar et al. 2015). However, high temperatures can result in unwanted colour changes as well as in the degradation of nutritionally interesting compounds such as polyphenols. In addition, consumers are now becoming more aware of the relationship between food, diet, and health, and this has led to increased interest in natural ingredients and development of mild processing technologies (Lafarga et al. 2018). Novel technologies with potential for being used in the food industry include high-pressure processing, pulsed electric fields, and thermosonication, a strategy that combines ultrasounds and mild temperatures. The microbial lethal effect of ultrasounds has been mainly attributed to the cavitation phenomenon (Khandpur and Gogate 2015).

81 Cavitational effects include intense localized pressure and temperature pulse as well as high intensity shear and turbulence and these can lead to the breakage of cell walls and damage of DNA resulting in deactivation of microorganisms (Khandpur and Gogate 2016). This technology has been suggested as a good alternative to thermal processing of, for example, carrot (Jabbar et al. 2015), watermelon (Rawson et al. 2011), or apple (Abid et al. 2014) juice.

The aim of this paper was to develop a novel tomato (Solanum Lycopersicum var. canario) juice enriched in anthocyanins using strawberry press cake and to evaluate the potential of thermosonication as an alternative to conventional thermal processing to provide a healthier, high quality, and safe product. Studied parameters included colour, $\mathrm{pH}$, soluble solids content (SSC), titratable acidity (TTA), total phenolic content (TPC), antioxidant activity, and total lycopene (TLC) and total anthocyanin content (TAC). 
93 Microorganisms and the activity of PG and PME were also studied. A secondary aim of

94 this study was to determine the bioaccessibility of phenolic and antioxidant compounds

95 using a simulated gastrointestinal digestion. 


\section{Materials and methods}

97

\subsection{Chemicals and reagents}

Methanol and ferric chloride were purchased from Panreac (Barcelona, Spain). Gallic acid, ascorbic acid, hydrochloride, 2,4,6-tris(2-pyridyl)-s-triazine, 2,2-diphenyl-1picrylhydrazyl (DPPH), tris(2-carboxyethyl)phosphine hydrochloride, potassium phosphate monobasic, potassium phosphate dibasic, sodium tetrachloropalladate, sodium acetate, sodium hydroxide, sodium chloride, peptone, $\alpha$-amylase (EC 3.2.1.1), pepsin (EC 3.4.23.1), and sodium carbonate were purchased from Sigma-Aldrich (Steinheim, Germany). Folin-Ciocalteu's reagent was purchased from VWR (Llinars del Vallès, Spain). Buffered peptone water and plate count agar (PCA) were purchased from Biokar (Beauvais, France). All reagents used were of analytical grade. Tomatoes used for juice making were purchased locally.

\subsection{Preparation of the functional anthocyanin-enriched tomato juice}

Strawberry press cake obtained after juice making was frozen, freeze-dried using a Crydos-50 freeze-dryer (Telstar, Barcelona, Spain), and stored at $-20^{\circ} \mathrm{C}$ until further use. The freeze-dried strawberry press cake was labelled as SPC. Two different types of juices were prepared: the control tomato and the anthocyanin-enriched tomato juice. Control tomato juice and anthocyanin-enriched juice were labelled as CJ and AEJ, respectively. The CJ was prepared using an Infinity Cold Press Revolution Juicer (Groupe SEB Iberica, Barcelona, Spain). Preliminary trials were carried out to establish the maximum SPC inclusion level that did not significantly affect the organoleptic properties of the juice. Following these trials, tomato juice containing SPC at concentrations ranging from 40 to $50 \mathrm{~g} / \mathrm{L}$ obtained the highest acceptability scores (data not shown). Therefore, the AEJ was prepared by incorporating $100 \mathrm{~g}$ of SPC, suspended in distilled water at a SPC:water ratio of 1:3 (w/v), into CJ until a final SPC concentration of $45 \mathrm{~g} / \mathrm{L}$ (35 g of SPC, $135 \mathrm{~mL}$ of 
121 water, and $865 \mathrm{~mL}$ of CJ per $1000 \mathrm{~mL}$ of AEJ). The amount of water in which the SPC

122 was resuspended was calculated to achieve a comparable water content in both juices, 123 determined as $93.1 \pm 0.2$ and $93.0 \pm 0.8 \%$ for $\mathrm{CJ}$ and AEJ, respectively. The CJ and AEJ

124 were homogeneized using a T-25 digital ULTRA-TURRAX ${ }^{\circledR}$ homogenizer (IKA,

125 Staufen, Germany) at 10,000 rpm for $1 \mathrm{~min}$ and stored at $4{ }^{\circ} \mathrm{C}$ during a 7 -day period.

\section{$126 \quad 2.3$ Juice processing}

127 Juice processing was carried out at the pilot plant facilities of IRTA Fruitcentre, Lleida, 128 Spain. Aliquots of $100 \mathrm{~mL}$ of AEJ were introduced in triplicate into $100 \mathrm{~mL}$ clear glass 129 flasks and were either left untreated (control, AEJ), thermally treated $\left(80^{\circ} \mathrm{C}, 1 \mathrm{~min}\right.$; P130 AEJ), or thermosonicated using a TI-H 20 stainless steel ultrasonic bath (Elma 131 Schmidbauer GmbH, Singen, Germany). Effective ultrasonic power was $250 \mathrm{~W}$ and the 132 tank internal dimensions and capacity were 330/300/200 mm (W/D/H) and $16.8 \mathrm{~L}$, 133 respectively. Thermosonication parameters studied included temperature $(20,40$, or 60

$\left.134{ }^{\circ} \mathrm{C}\right)$, processing duration $(0,5$, or $10 \mathrm{~min})$, and ultrasonic frequencies $(0,35$, or $130 \mathrm{kHz})$

135 at constant mode. Immediately after processing, samples were chilled to approximately 4 $136{ }^{\circ} \mathrm{C}$ using a ABT 101L blast chiller (Infrico, Barcelona, Spain) and stored at $4{ }^{\circ} \mathrm{C}$ in the 137 dark until further analysis. Analyses were performed at days 1 and 7 post-processing.

138 Treatment at $60{ }^{\circ} \mathrm{C}$ with ultrasounds at either 35 or $130 \mathrm{kHz}$ for $5 \mathrm{~min}$, which were found 139 to be the optimum conditions, were abbreviated as TS-AEJ.

\section{$140 \quad 2.4$ Microbiological analysis}

141 Total aerobic mesophilic microorganisms (TAM) were determined before and after 142 processing. Briefly, $25 \mathrm{~g}$ of sample were mixed in triplicate with $225 \mathrm{~mL}$ of buffered 143 peptone water in a $400 \mathrm{~mL}$ sterile full-page filter bag (Bagpage, Interscience, Saint Nom, 144 France). The mixture was homogenized in a Masticator Basic 400 (IUL, Barcelona, 145 Spain) at 8.5 strokes per s for $90 \mathrm{~s}$. Serial decimal dilutions were made in duplicate in 
146 saline peptone (sodium chloride $8.5 \mathrm{~g} / \mathrm{L}$, peptone $1 \mathrm{~g} / \mathrm{L}$ ) and plated on plate count agar

147 Petri dishes (PCA, Biokar Diagnostics, France). Plates were incubated at $30 \pm 1{ }^{\circ} \mathrm{C}$ for 3

148 days. Colony forming units (cfu) were counted and results were expressed as log cfu/g.

149 Reductions were calculated by subtracting the TAM population after treatment $(\log \mathrm{cfu} / \mathrm{g})$

150 from the initial one.

\section{$151 \quad 2.5$ Physicochemical characteristics}

152 Colour parameters were determined using a Minolta CR-200 colorimeter (Minolta INC,

153 Tokyo, Japan). CIE values were recorded in terms of $L^{*}$ (lightness), $a^{*}$ (redness,

154 greenness), and $b^{*}$ (yellowness/blueness). Calibration was carried out using a standard

155 white tile (Y:92.5, x:0.3161, y:0.3321) provided by the manufacturer and the D65

156 illuminant, which approximates to daylight. Chroma $\left(C^{*}\right.$ ab $)$ and difference from the

157 control $(\delta E)$ were calculated following the methodology described by Wibowo et al.

158 (2015). Results are the average of 10 measurements per treatment, sampling day, and

159 replicate.

160 The $\mathrm{pH}$ of the samples was measured using a Basic $20 \mathrm{pH}$ meter (Crison Instruments

161 S.A., Barcelona, Spain). To measure TTA, $10 \mathrm{~mL}$ of juice were diluted in $10 \mathrm{~mL}$ of

162 distilled water and were titrated with $0.1 \mathrm{~N}$ sodium hydroxide up to $\mathrm{pH}$ 8.2. Results are

163 the average of three measurements per treatment, sampling day, and replicate and were 164 expressed as g of malic acid per L.

165 SSC was measured at $20^{\circ} \mathrm{C}$ with a handheld refractometer (Atago Co. Ltd., Tokio, Japan).

166 Measurements were performed in triplicate per treatment, sampling day, and replicate and

167 results were expressed in ${ }^{\circ}$ Brix.

\section{$168 \quad 2.6$ Total phenolic content (TPC)}

169 The TPC was determined by the Folin Ciocalteu method as described by Altisent et al.

170 (2014) using a GENESYS ${ }^{\mathrm{TM}}$ 10S-UV Vis spectrophotometer (Thermo Fisher Scientific, 
171 MA, USA). TPC was determined in triplicate for each treatment, sampling day, and

172 replicate and results were expressed as mg of gallic acid equivalents per $100 \mathrm{~mL}$.

\section{$173 \quad 2.7$ Antioxidant activity: FRAP and DPPH・ scavenging activity}

174 Antioxidant activity was assessed using two different methods: the ferric ion reducing

175 antioxidant power (FRAP) and the DPPH scavenging activity assays following the 176 methodologies previously described by Plaza et al. (2016) and Hidalgo et al. (2010),

177 respectively. Antioxidant activity was determined in triplicate for each treatment, 178 sampling day, and replicate and results were expressed as mg of ascorbic acid equivalents 179 per $100 \mathrm{~mL}$.

$180 \quad 2.8$ Total anthocyanin content (TAC)

181 The TAC was determined following the methodology previously described by Meyers et 182 al. (2003) using a spectrophotometer. TAC was determined in triplicate for each 183 treatment, sampling day, and replicate and results were expressed as mg of cyanidin 3184 glucoside equivalents per $100 \mathrm{~mL}$.

\subsection{Total lycopene content (TLC)}

186 The TLC was determined following the methodology previously described by Fish et al.

187 (2002) using a spectrophotometer. TLC was determined in triplicate for each treatment, 188 sampling day, and replicate and results were expressed as $\mathrm{mg}$ of lycopene per $100 \mathrm{~mL}$.

\subsection{Enzymatic activity}

190 The activity of the enzyme PG was determined following the methodology of Sila et al.

191 (2008) with brief modifications as described by Zudaire et al. (2018). In addition, the

192 activity of the enzyme PME was determined following the method described by Plaza et

193 al. (2016) with some modifications as described in Zudaire et al. (2018). The activity of 
194 both enzymes was expressed as PG or PME units per mL. PME and PG units were defined

195 as the amount of enzyme required to release $1 \mu \mathrm{mol}$ of carboxyl or reducing groups per $196 \min$

\section{$197 \quad$ 2.11 Simulated gastrointestinal digestion}

198 A simulated gastrointestinal digestion of AEJ, P-AEJ, and TS-AEJ was performed at day

1997 post-processing following the methodology previously described by Minekus et al.

200 (2014). The methodology consists of three sequential stages including oral ( $\alpha$-amylase,

$201 \mathrm{pH}$ 7.0), gastric (pepsin, $\mathrm{pH} 3.0$ ), and intestinal (pancreatin and fresh bile, $\mathrm{pH}$ 7.0) phases.

202 Digestions and determinations of TPC and antioxidant activity were carried out after

203 gastric and intestinal phases and determined in triplicate for each treatment and replicate.

\section{$204 \quad 2.12$ Statistical analysis}

205 Results are expressed as mean \pm standard deviation (S.D.). A multifactorial design with

206 storage period and treatment factors was used to analyse the results. Data were analysed 207 using analysis of variance (ANOVA) with JMP 13 (SAS Institute Inc., Cary, USA). 208 Where significant differences of storage period or treatment time were found, a Tukey 209 pairwise comparison of the means was conducted to identify where the sample differences 210 occurred. The criterion for statistical significance was $p<0.05$. 


\section{Results and discussion}

$212 \quad 3.1$ Effect of strawberry co-product inclusion into tomato juice

213 Strawberries are rich sources of anthocyanins (Ma et al. 2018) and as expected, 214 incorporation of SPC into tomato juice resulted in increased TAC $(p<0.05)$. The TAC of

$215 \mathrm{CJ}$ and untreated AEJ at day 1 was $0.09 \pm 0.01$ and $1.08 \pm 0.04 \mathrm{mg} / 100 \mathrm{~mL}$, respectively.

216 In addition, the AEJ showed a lower TLC $(2.02 \pm 0.10 \mathrm{mg} / 100 \mathrm{~mL})$ when compared to

217 CJ $(2.38 \pm 0.07 \mathrm{mg} / 100 \mathrm{~mL}, p<0.05)$, because of the dilution of the lycopene found in CJ

218 after addition of water and strawberry co-products. AEJ also showed higher TPC and

219 antioxidant activity when compared with the control $(p<0.05)$. The TPC of the CJ and

220 AEJ was $24.03 \pm 1.02$ and $57.25 \pm 2.39 \mathrm{mg} / 100 \mathrm{~mL}$ respectively $(p<0.05)$. FRAP and

$221 \mathrm{DPPH} \cdot$ values of AEJ were $73.01 \pm 0.82$ and $51.84 \pm 4.05 \mathrm{mg} / 100 \mathrm{~mL}$. These were higher

222 than those of $\mathrm{CJ}$, which were $31.26 \pm 1.86$ and $24.39 \pm 1.24 \mathrm{mg} / 100 \mathrm{~mL}$ respectively

$223(p<0.05)$. Several studies demonstrated the bioactive properties of anthocyanin-rich 224 extracts and foods (Ma et al. 2018; Zhao et al. 2015). Results reported in the current paper 225 compared well with those obtained in previous studies, which demonstrated that 226 anthocyanin-rich products and extracts could increase the health benefits of foods and 227 show potential for being used as novel ingredients for the development of functional 228 foods. Kamiloglu et al. (2017) showed that enrichment of cake flour with black carrot 229 pomace, at concentrations ranging from 50 to $150 \mathrm{~g} / \mathrm{kg}$, caused a dose-dependent increase 230 in anthocyanins, total phenolics, and total antioxidant capacity. Pineda-Vadillo et al. 231 (2016) also reported increased in vitro antioxidant activity of dairy and egg products 232 enriched with grape extracts rich in anthocyanins and other polyphenols. Anthocyanin233 rich ingredients can increase the health benefits of foods beyond their polyphenolic 234 content and antioxidant capacity. Indeed, Sui et al. (2016) recently reported that 
235 enrichment of bread with an anthocyanin-rich extract from black rice reduced the

236 digestibility rate of the product providing it with extra health benefits.

237 Colour attributes and other physiochemical parameters, listed in Table 1, were also

238 affected after incorporation of SPC into CJ. The $L^{*}$ value was higher in AEJ when 239 compared to $\mathrm{CJ}(p<0.05)$. This denotes a lighter appearance of the juice after 240 incorporation of SPC into the tomato juice. In addition, incorporation of SPC into the 241 tomato juice also resulted in increased red hue $(p<0.05)$. No differences were observed in $242 C_{a b} *$ values, which means that that CJ and AEJ had a comparable colour intensity. $\delta E$ 243 combines the change in $L^{*}, a^{*}$, and $b^{*}$ values to quantify the colour deviation from a 244 standard reference sample, in this case, to compare the colour difference between CJ and 245 AEJ. Those samples with $\delta E>3$ display a visible colour deviation (Wibowo et al. 2015).

246 As expected, both juices exhibited a visible colour deviation. Incorporation of SPC into 247 the tomato juice also resulted in decreased $\mathrm{pH}(p<0.05)$. The opposite trend was observed 248 for TTA and SSC $(p<0.05)$. Finally, a separation layer was observed during storage of CJ 249 (not measured). However, incorporation of SPC into CJ gave no phase separation during 250 storage for 7 days at $4{ }^{\circ} \mathrm{C}$.

251 Overall, incorporation of SPC into tomato juice, at the concentration evaluated herein, 252 resulted in a stable product with a significantly higher nutritional quality. Some physicochemical properties such as SSC, TTA, pH, or colour were significantly affected

254 after addition of SPC into the CJ.

3.2 Effect of conventional thermal processing and thermosonication on juice microbiological quality

257 In order to assess the effect of different thermosonication conditions on the 258 microorganisms on the juice, the survival rates of TAM counts were analysed. 259 Preliminary trials were carried out at different temperatures $\left(20,40\right.$, or $\left.60{ }^{\circ} \mathrm{C}\right)$, durations 
260 (5 or $10 \mathrm{~min})$, and frequencies $(0,35$, or $130 \mathrm{kHz}$ ). Khandpur and Gogate (2015) suggested that a controlled application of ultrasounds is required in order to maximize the degree of microbial inactivation and minimize the loss of nutrient quality and avoid to stimulate enzymes. In the current study, the thermosonication process was not optimised, and further studies are needed in order to select the conditions that would permit higher antimicrobial effects and higher retention of bioactive compounds. A response surface methodology varying frequency, temperature, duration, and power would allow to obtain optimum conditions. No effect on microbial inactivation was observed with respect to frequencies or duration. However, differences were observed with respect to temperature and the combined effect of temperature and ultrasounds $(p<0.05)$. Initial TAM count of AEJ was $6.3 \pm 0.2 \log \mathrm{cfu} / \mathrm{g}$. Thermal processing at $80^{\circ} \mathrm{C}$ for $1 \mathrm{~min}$ resulted in reductions in the total aerobic mesophilic organisms count of 2.4 and $3.3 \log \mathrm{cfu} / \mathrm{g}$ at days 1 and 7 (Figure 1A and 1B, respectively). Operating at $20^{\circ} \mathrm{C}$ had no effect on the microbial load of the samples when compared with the untreated juice. Moreover, the microbial load of samples sonicated for $5 \mathrm{~min}$ at $20{ }^{\circ} \mathrm{C}$ after 7 days of storage at $4{ }^{\circ} \mathrm{C}$ was higher when compared to the samples treated at $20^{\circ} \mathrm{C}$ for $5 \mathrm{~min}$ and not sonicated $(p<0.05)$. The observed increase could be caused by a liberation of carbohydrates and other compounds which promote the growth of the microorganisms that survived to the process, as the application of ultrasounds for assisting extraction of phytochemicals and other organic compounds from plant material has been widely published. In addition, sonication can

280 disaggregate microbial cell aggregates resulting in more than one cfu from each initial 281 cfu. Although no lethal effect was observed when operating at $20^{\circ} \mathrm{C}$, sonication at $40{ }^{\circ} \mathrm{C}$ resulted in a low but significant reduction in the TAM count (Figure $1 ; p<0.05$ ). Reductions ranged between 0.40 and $0.46 \log \mathrm{cfu} / \mathrm{g}$ at day 1 and 0.18 and $0.64 \log \mathrm{cfu} / \mathrm{g}$ at day 7 depending on the frequencies and process durations used. Thermal treatment of 
285 the juice at $40{ }^{\circ} \mathrm{C}$ for $5 \mathrm{~min}$, with no sonication, resulted in a no reduction in the TAM 286 count at day 1 and a reduction of $0.31 \log \mathrm{cfu} / \mathrm{g}$ at day 7 , suggesting a synergetic effect 287 of temperature and ultrasounds. It has been suggested that ultrasounds enhance the 288 sensitivity of microorganisms to heat, pressure, and acidic conditions due to acoustic 289 cavitation and modifications in their cell membrane (Bermúdez-Aguirre and Barbosa290 Cánovas 2012). The same trend was observed when processing at $60{ }^{\circ} \mathrm{C}$. The lethal effect 291 of temperature $\left(60^{\circ} \mathrm{C}\right)$ combined with ultrasounds $(35$ or $130 \mathrm{kHz}$ for 5 or $10 \mathrm{~min})$ was 292 higher when compared to that of sonication or thermal processing alone $(p<0.05)$.

293 Observed reductions were even bigger than those obtained after thermal processing at 80 $294{ }^{\circ} \mathrm{C}$ for $1 \mathrm{~min}$, especially after 7 days of storage at $4{ }^{\circ} \mathrm{C}(p<0.05)$. TAM counts of AEJ 295 treated at $60{ }^{\circ} \mathrm{C}$ with or without sonication, decreased during storage with total reductions 296 of $5.1 \pm 0.1$ and $5.7 \pm 0.1 \log \mathrm{cfu} / \mathrm{g}$, which resulted in a final population of $3.3 \pm 0.1$ and $2972.6 \pm 0.1 \log \mathrm{cfu} / \mathrm{g}$ at day 7 , respectively. This could be due to the fact that at $60{ }^{\circ} \mathrm{C}$, some 298 injured microorganisms did not survive storage due to the harsh environment encountered 299 in the AEJ (low pH and temperature, high acidity, and no oxygen). Similar results were 300 observed after thermosonication $(20 \mathrm{kHz}, 750 \mathrm{~W})$ at $60{ }^{\circ} \mathrm{C}$ of carrot (Jabbar et al. 2015) 301 or apple (Abid et al. 2013) juice. Results were also in line with those reported by Kiang 302 et al. (2013) who evaluated the effect of thermosonication $(25 \mathrm{kHz}, 200 \mathrm{~W})$ on the human 303 pathogens Escherichia coli O157:H7 and Salmonella Enteriditis. In that study, the authors 304 reported that Salmonella Enteriditis was not recovered in samples subjected to 305 thermosonication at $60^{\circ} \mathrm{C}$ for more than $5 \mathrm{~min}$.

306 Overall, thermosonication for $5 \mathrm{~min}$ at $60{ }^{\circ} \mathrm{C}$ and either 35 or $130 \mathrm{kHz}$ allowed a higher 307 reduction in the microbial load of AEJ when compared to a pasteurization treatment at 80 $308{ }^{\circ} \mathrm{C}$ for $1 \mathrm{~min}$. The observed reduction was especially higher at day 7 ( $p<0.05$ ). In addition, 
309 the combined antimicrobial effect of temperature and ultrasounds was higher when

310 compared to both strategies alone.

3113.3 Effect of conventional thermal processing and thermosonication on juice 312 enzymatic and physicochemical quality

313 Based on microbiological results, thermosonication treatments at $60{ }^{\circ} \mathrm{C}$ for $5 \mathrm{~min}$ at 35 or

$314130 \mathrm{kHz}$ were selected for further studies. No differences were observed in the enzymatic,

315 physiochemical, and nutritional properties of juices treated by either 35 or $130 \mathrm{kHz}$ and

316 therefore, results shown in this section are the average of both treatments.

317 Thermosonication and cold storage had no effect on the $\mathrm{pH}$, TTA, and SSC of the juice

318 when compared to the fresh untreated juice (Table 1). Similar results were published

319 previously (Jabbar et al. 2015; Abid et al. 2013; Walkling-Ribeiro et al. 2009). As

320 mentioned previously, those samples with $\delta E>3$ displayed a well visible colour deviation

321 (Cserhalmi et al. 2006). Therefore, according to Cserhalmi et al. (2006) colour deviations

322 caused by thermosonication were not visible for any of the sampling days assayed.

323 Thermal processing resulted in no differences in colour $24 \mathrm{~h}$ after processing (P-AEJ,

324 Table 1), but differences were visible at day $7(\delta E>3)$, suggesting a better retention of

325 physicochemical properties in the thermosonicated juice when compared to the thermally

326 treated one. Probably, colour changes were caused by a degradation of pigments such as

327 lycopene and anthocyanins caused by temperature and storage.

328 Endogenous enzymes found in fruits are responsible for changes in their postharvest

329 quality. Enzymes like PG and PME are involved in breakdown of pectin and other cell

330 wall materials, resulting in products with reduced viscosity and undesirable organoleptic

331 properties (Chakraborty et al. 2015). The effect of thermosonication and thermal

332 processing on the activity of the enzymes PG and PME in the AEJ is shown in Figure 2.

333 The activity of both enzymes after processing showed a similar trend. Thermal processing 
334 significantly reduced the activity of both PG and PME at days 1 and 7 when compared to

335 the untreated control $(p<0.05)$. Thermosonication of the juice also decreased the activity 336 of PME at day $1(p<0.05)$ but the observed decrease was significantly lower when

337 compared to conventional thermal processing $(p<0.05)$. Enzymatic inactivation by 338 thermosonication has been attributed to the combined effect of temperature and to the 339 chemical and mechanical effects induced by cavitation and high shear forces produced by

340 bubble implosions with acoustic field (Ercan and Soysal 2011). Free radicals produced 341 by sonication can also oxidize enzymes reducing their activity (Terefe et al. 2009).

342 Similar results were reported by Jabbar et al. (2015) after thermal processing $\left(80{ }^{\circ} \mathrm{C}, 1\right.$ $343 \mathrm{~min})$ and thermosonication $\left(20,40\right.$, or $60^{\circ} \mathrm{C}$ for 5 or $\left.10 \mathrm{~min}\right)$ of carrot juice. In that study,

344 the authors assessed the enzymatic activity after processing and not during storage. In the

345 current paper, the activity of both PG and PME increased in TS-AEJ at day 7 and was 346 even higher than that measured in AEJ $(p<0.05)$. Results obtained in the current paper 347 suggest that thermosonication has a lower enzyme inactivation capacity when compared 348 to conventional pasteurization. However, previous studies suggested that the inactivation 349 of enzymes by thermosonication is time-dependent (Rithmanee and Intipunya 2012;

350 Ercan and Soysal 2011; Jabbar et al. 2015). Therefore, although long processing times 351 are not feasible at industrial scale, further studies could assess the effect of longer 352 thermosonication processes on the activity of both PG and PME of the AEJ developed 353 herein.

\section{$354 \quad 3.4$ Total phenolic content and antioxidant activity}

355 Figure 3 shows the effect of thermosonication on the TPC and antioxidant activity of the 356 AEJ. The TPC of both P-AEJ and TS-AEJ was lower when compared to that of untreated 357 AEJ ( $p<0.05$; Figure 3A). However, the TPC of the thermally treated juice was lower 358 when compared to that of the thermosonicated juices $(p<0.05)$. This means that 
thermosonication for $5 \mathrm{~min}$ at $60{ }^{\circ} \mathrm{C}$ and either 35 or $130 \mathrm{kHz}$ resulted in better retention

360 of polyphenols when compared to thermal processing at $80^{\circ} \mathrm{C}$ for $1 \mathrm{~min}$. After 7 days of storage at $4{ }^{\circ} \mathrm{C}$, TPC content significantly decreased in all samples, but TS-AEJ showed

362 the highest value which was $45.6 \pm 1.1 \mathrm{mg} / 100 \mathrm{~mL}(p<0.05)$.

363 Results obtained for antioxidant activity correlated well with those obtained for TPC. No

364 differences were detected in the antioxidant potential of AEJ and TS-AEJ at day 1 when

365 assessed using the DPPH - assay (Figure 3C). Thermosonication resulted in increased

366 FRAP values when compared to the control ( $p<0.05$; Figure $3 \mathrm{~B})$, probably caused by a

367 higher amount of antioxidant compounds in the water:methanol extracts as ultrasounds

368 have been repeatedly used to increase the extraction of bioactive compounds from foods

369 (Barba et al. 2016; Chemat et al. 2017). Both FRAP and DPPH. values of the P-AEJ were

370 lower when compared to AEJ and P-AEJ $(p<0.05)$, supporting previous results which suggested that thermosonication resulted in better retention of nutritional properties when compared to thermal processing (Escudero-López et al. 2016; Chen et al. 2015; Khandpur and Gogate 2015, 2016).

\subsection{Total anthocyanin and lycopene content}

375 The TLC (Figure 4A) of P-AEJ was lower than that of the AEJ and TS-AEJ at days 1 and

$3767(p<0.05)$. No differences were observed between the TLC of the CJ and the TS-AEJ, 377 suggesting that thermosonication at $60^{\circ} \mathrm{C}$, at 35 or $130 \mathrm{kHz}$, for $5 \mathrm{~min}$ had no effect on 378 the lycopene content of the juice. Lycopene has a strong red colour and the observed 379 degradation of lycopene after thermal processing could explain the measured colour 380 change in P-AEJ when compared to AEJ. In addition, the TLC of all samples decreased 381 during storage at $4{ }^{\circ} \mathrm{C}$ for 7 days $(p<0.05)$.

382 A similar trend was detected for the TAC (Figure 4B), which was significantly lower $(p<0.05)$ for P-AEJ $(0.92 \pm 0.01 \mathrm{mg} / 100 \mathrm{~mL})$ when compared to AEJ $(1.08 \pm 0.04 \mathrm{mg} / 100$ 
$\mathrm{mL})$ and TS-AEJ $(1.06 \pm 0.03 \mathrm{mg} / 100 \mathrm{~mL})$. No differences were observed between the

385 TAC of the AEJ and TS-AEJ, suggesting no degradation of anthocyanins caused by 386 thermosonication. However, the TAC of all samples decreased during storage at $4{ }^{\circ} \mathrm{C}$ for

3877 days, and the observed decrease in TAC was higher for P-AEJ (83.4\%) when compared 388 to AEJ and TS-AEJ: 81.2 and 81.6\%, respectively $(p<0.05)$. Cano-Lamadrid et al. (2017) 389 also experienced significant reductions in the anthocyanin content during cold storage of 390 a fermented milk product enriched in anthocyanins using pomegranate juice.

\section{$391 \quad 3.6$ In vitro gastrointestinal digestion}

Previous studies demonstrated that the amount of health-promoting compounds released by foods during digestion, especially during the intestinal phase, might be higher than the one expected from common water-organic extracts (Pérez-Jiménez and Saura-Calixto 2005). However, other papers suggested that polyphenols are degraded during digestion and that their bioaccessibility could be limited (Zudaire et al. 2017). In the current study, both the TPC and the antioxidant capacity, assessed using the FRAP or DPPH - method, decreased during the simulated digestion (Figure $5 ; p<0.05$ ). The TPC of the P-AEJ (Figure 5A) after the intestinal phase of digestion was lower when compared to that of

400 AEJ and TS-AEJ (Figure 5A; $p<0.05$ ). Results suggest that both processing technologies 401 limit the bioaccessibility of phenolic compounds. However, the observed decrease in 402 bioaccessibility was higher after thermal processing when compared to thermosonication. Similar results were observed with respect to antioxidant activity. Antioxidant capacity, measured as FRAP (Figure 5B) or DPPH (Figure 5C) after the intestinal phase was lower

405 in processed P-AEJ and TS-AEJ when compared to the untreated AEJ $(p<0.05)$.

406 However, no significant differences were observed between both processed samples 407 besides a slightly higher FRAP value after the intestinal phase in P-AEJ $(p<0.05)$. 408 Polyphenols are highly sensitive to alkaline conditions (Chen et al. 2014). Therefore, after 
409 the intestinal digestion phase, polyphenols could have been degraded by the alkaline $\mathrm{pH}$,

410 thus leading to the observed loss in the TPC and the antioxidant capacity as previously 411 reported by Bermúdez-Soto et al. (2007). 


\section{4. Conclusions}

413 The anthocyanin-enriched tomato juice developed herein showed not only higher

414 nutritional properties but also improved physiochemical properties, which were

415 comparable to those of currently commercialized fruit juices. Moreover, this enriched

416 tomato juice has the advantage of using strawberry co-products, increasing its added value

417 and sustainability. Results obtained in the current paper support previous studies which

418 suggested that thermosonication could be used to minimize the degradation of phenolic

419 compounds during processing and retain the antioxidant capacity of fruit juices. Fruit

420 processing by either a conventional thermal treatment or by thermosonication resulted in

421 a lower amount of phenolic compounds in the extracts obtained using water and methanol

422 and also in the enzymatic extracts obtained after a simulated gastrointestinal digestion.

423 Moreover, microbial inactivation is of key importance in order to produce safe products.

424 Thermosonication at either 35 or $130 \mathrm{kHz}$ for $5 \mathrm{~min}$ at $60^{\circ} \mathrm{C}$ resulted in higher reductions

425 in the total aerobic mesophilic organisms count when compared to a conventional

426 pasteurization process. Therefore, based on the results reported herein, we can conclude

427 that thermosonication could be used a suitable strategy to obtain healthier and safer juices.

428 Optimization of the thermosonication conditions using a response surface methodology

429 could improve the retention of bioactive and nutritious compounds and the observed

430 lethal effects. 


\section{Acknowledgements}

432 This work was supported by the CERCA Programme of Generalitat de Catalunya. T.

433 Lafarga is in receipt of Juan de la Cierva contract awarded by the Spanish Ministry of 434 Economy, Industry, and Competitiveness (FJCI-2016-29541). I. Aguiló-Aguayo thanks 435 the Spanish Ministry of Economy, Industry, and Competitiveness and to the European 436 Social Fund for the Postdoctoral Senior Grant Ramon y Cajal (RYC-2016-19949). 437 Authors thank Isabel Ruiz and Silvia Villaró for their technical assistance.

438 
440 Abid M, Jabbar S, Hu B, Hashim MM, Wu T, Lei S, Khan MA \& Zeng X (2014)

441

442

443

444

445

446

447

448

449

450

451

452

453

454

455

456

457

458

459

460

461

462

463

464

465

466

467

468

469

470

471

472

473

474

475

476

477

478

479

480

481

Thermosonication as a potential quality enhancement technique of apple juice. Ultrasonics Sonochemistry. 21(3), 984-990.

Abid M, Jabbar S, Wu T, Hashim MM, Hu B, Lei S, Zhang X \& Zeng X (2013) Effect of ultrasound on different quality parameters of apple juice. Ultrasonics Sonochemistry. 20(5), 1182-1187.

Altisent R, Plaza L, Alegre I, Viñas I \& Abadias M (2014) Comparative study of improved vs. traditional apple cultivars and their aptitude to be minimally processed as 'ready to eat'apple wedges. LWT-Food Science and Technology. 58(2), 541-549.

Barba FJ, Zhu Z, Koubaa M, Sant'Ana AS \& Orlien V (2016) Green alternative methods for the extraction of antioxidant bioactive compounds from winery wastes and byproducts: a review. Trends in Food Science \& Technology. 49, 96-109.

Bermúdez-Aguirre D \& Barbosa-Cánovas GV (2012) Inactivation of Saccharomyces cerevisiae in pineapple, grape and cranberry juices under pulsed and continuous thermo-sonication treatments. Journal of Food Engineering. 108(3), 383-392.

Bermúdez-Soto M-J, Tomás-Barberán F-A \& García-Conesa M-T (2007) Stability of polyphenols in chokeberry (Aronia melanocarpa) subjected to in vitro gastric and pancreatic digestion. Food Chemistry. 102(3), 865-874.

Bueno JM, Sáez-Plaza P, Ramos-Escudero F, Jiménez AM, Fett R \& Asuero AG (2012) Analysis and antioxidant capacity of anthocyanin pigments. Part II: chemical structure, color, and intake of anthocyanins. Critical Reviews in Analytical Chemistry. 42(2), 126-151.

Cano-Lamadrid M, Trigueros L, Wojdyło A, Carbonell-Barrachina ÁA \& Sendra E (2017) Anthocyanins decay in pomegranate enriched fermented milks as a function of bacterial strain and processing conditions. LWT - Food Science and Technology. 80, 193-199.

Cassidy A, O’Reilly ÉJ, Kay C, Sampson L, Franz M, Forman J, Curhan G \& Rimm EB (2010) Habitual intake of flavonoid subclasses and incident hypertension in adults-. The American Journal of Clinical Nutrition. 93(2), 338-347.

Chakraborty S, Baier D, Knorr D \& Mishra HN (2015) High pressure inactivation of polygalacturonase, pectinmethylesterase and polyphenoloxidase in strawberry puree mixed with sugar. Food and Bioproducts Processing. 95, 281-291.

Chemat F, Rombaut N, Sicaire A-G, Meullemiestre A, Fabiano-Tixier A-S \& Abert-Vian M (2017) Ultrasound assisted extraction of food and natural products. Mechanisms, techniques, combinations, protocols and applications. A review. Ultrasonics Sonochemistry. 34, 540-560.

Chen G-L, Chen S-G, Zhao Y-Y, Luo C-X, Li J \& Gao Y-Q (2014) Total phenolic contents of 33 fruits and their antioxidant capacities before and after in vitro digestion. Industrial Crops and Products. 57, 150-157.

Chen X, Qin W, Ma L, Xu F, Jin P \& Zheng Y (2015) Effect of high pressure processing and thermal treatment on physicochemical parameters, antioxidant activity and 
volatile compounds of green asparagus juice. LWT - Food Science and Technology. 62, 927-933.

Cserhalmi Z, Sass-Kiss A, Tóth-Markus M \& Lechner N (2006) Study of pulsed electric field treated citrus juices. Innovative Food Science \& Emerging Technologies. 7(1-2), 49-54.

Ercan SŞ \& Soysal Ç (2011) Effect of ultrasound and temperature on tomato peroxidase. Ultrasonics Sonochemistry. 18(2), 689-695.

Escudero-López B, Cerrillo I, Gil-Izquierdo Á, Hornero-Méndez D, Herrero-Martín G, Berná G, Medina S, Ferreres F, Martín F \& Fernández-Pachón M-S (2016) Effect of thermal processing on the profile of bioactive compounds and antioxidant capacity of fermented orange juice. International Journal of Food Sciences and Nutrition. 67(7), 779-788.

Fernandes A, Rocha MAA, Santos LMNBF, Brás J, Oliveira J, Mateus N \& de Freitas V (2018) Blackberry anthocyanins: $\beta$-Cyclodextrin fortification for thermal and gastrointestinal stabilization. Food Chemistry. 245, 426-431.

Fish WW, Perkins-Veazie P \& Collins JK (2002) A quantitative assay for lycopene that utilizes reduced volumes of organic solvents. Journal of Food Composition and Analysis. 15(3), 309-317.

Gültekin-Özgüven M, Karadağ A, Duman Ş, Özkal B \& Özçelik B (2016) Fortification of dark chocolate with spray dried black mulberry (Morus nigra) waste extract encapsulated in chitosan-coated liposomes and bioaccessability studies. Food Chemistry. 201, 205-212.

Hidalgo M, Sánchez-Moreno C \& de Pascual-Teresa S (2010) Flavonoid-flavonoid interaction and its effect on their antioxidant activity. Food Chemistry. 121(3), 691-696.

Jabbar S, Abid M, Hu B, Hashim MM, Lei S, Wu T \& Zeng X (2015) Exploring the potential of thermosonication in carrot juice processing. Journal of Food Science and Technology. 52(11), 7002-7013.

Kamiloglu S, Ozkan G, Isik H, Horoz O, Van Camp J \& Capanoglu E (2017) Black carrot pomace as a source of polyphenols for enhancing the nutritional value of cake: An in vitro digestion study with a standardized static model. LWT - Food Science and Technology. 77, 475-481.

Khandpur P, Gogate PR (2015) Effect of novel ultrasound based processing on nutrition quality of different fruit and vegetables juices. Ultrasonics Sonochemistry. 27, 125-136.

Khandpur P, Gogate PR (2016) Evaluation of ultrasound based sterilization approaches in terms of shelf life and quality parameters of fruit and vegetables juices. Ultrasonics Sonochemistry. 29, 337-353.

Kiang WS, Bhat R, Rosma A \& Cheng LH (2013) Effects of thermosonication on the fate of Escherichia coli O157: $\mathrm{H7}$ and Salmonella Enteritidis in mango juice. Letters in Applied Microbiology. 56(4), 251-257.

Lafarga T, Viñas I, Bobo G, Simó J \& Aguiló-Aguayo I (2018) Effect of steaming and sous vide processing on the total phenolic content, vitamin $\mathrm{C}$ and antioxidant potential of the genus Brassica. Innovative Food Science \& Emerging Technologies. 47, 412-420. 
Ma H, Johnson SL, Liu W, DaSilva NA, Meschwitz S, Dain JA \& Seeram NP (2018) Evaluation of polyphenol anthocyanin-enriched extracts of blackberry, black

Plaza L, Altisent R, Alegre I, Viñas I \& Abadias M (2016) Changes in the quality and antioxidant properties of fresh-cut melon treated with the biopreservative culture Pseudomonas graminis CPA-7 during refrigerated storage. Postharvest Biology and Technology. 111, 25-30.

Rawson A, Tiwari BK, Patras A, Brunton N, Brennan C, Cullen PJ \& O'Donnell C (2011) Effect of thermosonication on bioactive compounds in watermelon juice. Food Research International. 44(5), 1168-1173.

Rithmanee T \& Intipunya P (2012) Effects of high power ultrasonic pretreatment on physicochemical quality and enzymatic activities of dried longan. Journal of Agricultural Science. 4(11), 299.

Šaponjac VT, Gironés-Vilaplana A, Djilas S, Mena P, Ćetković G, Moreno DA, Čanadanović-Brunet J, Vulić J, Stajčića S \&Vinčića M (2015) Chemical 
composition and potential bioactivity of strawberry pomace. RSC Advances. 5(7), 5397-5405.

Sila DN, Duvetter T, De Baerdemaeker J \& Hendrickx M (2008) Effect of mechanical impact-bruising on polygalacturonase and pectinmethylesterase activity and pectic cell wall components in tomato fruit. Postharvest Biology and Technology. 47(1), 98-106.

Sui X, Zhang Y \& Zhou W (2016) Bread fortified with anthocyanin-rich extract from black rice as nutraceutical sources: Its quality attributes and in vitro digestibility. Food Chemistry. 196, 910-916.

Terefe NS, Gamage M, Vilkhu K, Simons L, Mawson R \& Versteeg C (2009) The kinetics of inactivation of pectin methylesterase and polygalacturonase in tomato juice by thermosonication. Food Chemistry. 117(1), 20-27.

Walkling-Ribeiro M, Noci F, Riener J, Cronin D, Lyng J \& Morgan D (2009) The impact of thermosonication and pulsed electric fields on Staphylococcus aureus inactivation and selected quality parameters in orange juice. Food and Bioprocess Technology. 2(4), 422.

Wibowo S, Vervoort L, Tomic J, Santiago JS, Lemmens L, Panozzo A, Grauwet T, Hendrickx M \& Van Loey A (2015) Colour and carotenoid changes of pasteurised orange juice during storage. Food Chemistry. 171, 330-340.

Zhao M, Wang P, Zhu Y, Liu X, Hu X \& Chen F (2015) Blueberry anthocyanins extract inhibits acrylamide-induced diverse toxicity in mice by preventing oxidative stress and cytochrome P450 2E1 activation. Journal of Functional Foods. 14, 95101.

Zudaire L, Viñas I, Abadias M, Simó J, Echeverria G, Plaza L \& Aguiló-Aguayo I (2017) Quality and bioaccessibility of total phenols and antioxidant activity of calçots (Allium cepa L.) stored under controlled atmosphere conditions. Postharvest Biology and Technology. 129, 118-128.

Zudaire L, Viñas I, Plaza L, Iglesias MB, Abadias M \& Aguiló-Aguayo I (2018) Evaluation of postharvest calcium treatment and biopreservation with Lactobacillus rhamnosus GG on the quality of fresh-cut 'Conference'pears. Journal of the Science of Food and Agriculture. 98, 4978-4987. 
603 Figure 1. Effect of processing on the total aerobic mesophilic microorganisms count 604 at days 1 (A) and 7 (B)

605 TT-1: Thermal processing at $80^{\circ} \mathrm{C}$ for $1 \mathrm{~min}$; TT-5: Thermal processing at either 60,40 , $60620^{\circ} \mathrm{C}$ for $5 \mathrm{~min}$; TS-5: Thermosonication (at either 35 or $130 \mathrm{kHz}$ ) at 60,40 , or $20^{\circ} \mathrm{C}$ for

$6075 \mathrm{~min}$. Values represent the mean of three independent experiments \pm S.D. Different 608 letters indicate significant differences between treatments at the same sampling day. The 609 criterion for statistical significance was $p<0.05$.

610 Figure 2. Effect of processing on the activity of (A) PG and (B) PME

611 Values represent the mean of three independent experiments \pm S.D. Capital letters 612 indicate significant differences between treatments at the same sampling day. Lower case

613 letters indicate significant differences between sampling days for the treatment. The 614 criterion for statistical significance was $p<0.05$.

615 Figure 3. Effect of processing on the (A) TPC and antioxidant activity when assessed 616 using the (B) FRAP and (C) DPPH• assays

617 Values represent the mean of three independent experiments \pm S.D. Capital letters

618 indicate significant differences between treatments at the same sampling day. Lower case 619 letters indicate significant differences between sampling days for the treatment. The 620 criterion for statistical significance was $p<0.05$.

621 Figure 4. Effect of processing on the (A) TLC and (B) TAC

622 Values represent the mean of three independent experiments \pm S.D. Capital letters 623 indicate significant differences between treatments at the same sampling day. Lower case 
624 letters indicate significant differences between sampling days for the treatment. The 625 criterion for statistical significance was $p<0.05$.

626 Figure 5. Resistance of (A) polyphenols and antioxidant activity, assessed using (B)

627 FRAP and (C) DPPH• assays, to a simulated gastrointestinal digestion

628 Values represent the mean of three independent experiments \pm S.D. Capital letters

629 indicate significant differences between treatments at the same phase of digestion. Lower

630 case letters indicate significant differences between digestive phases for the same

631 treatment. The criterion for statistical significance was $p<0.05$. 
$632 \quad$ Figure 1

(A)

Temperature $\left[{ }^{\circ} \mathrm{C}\right]$

$60 \quad 40$

20

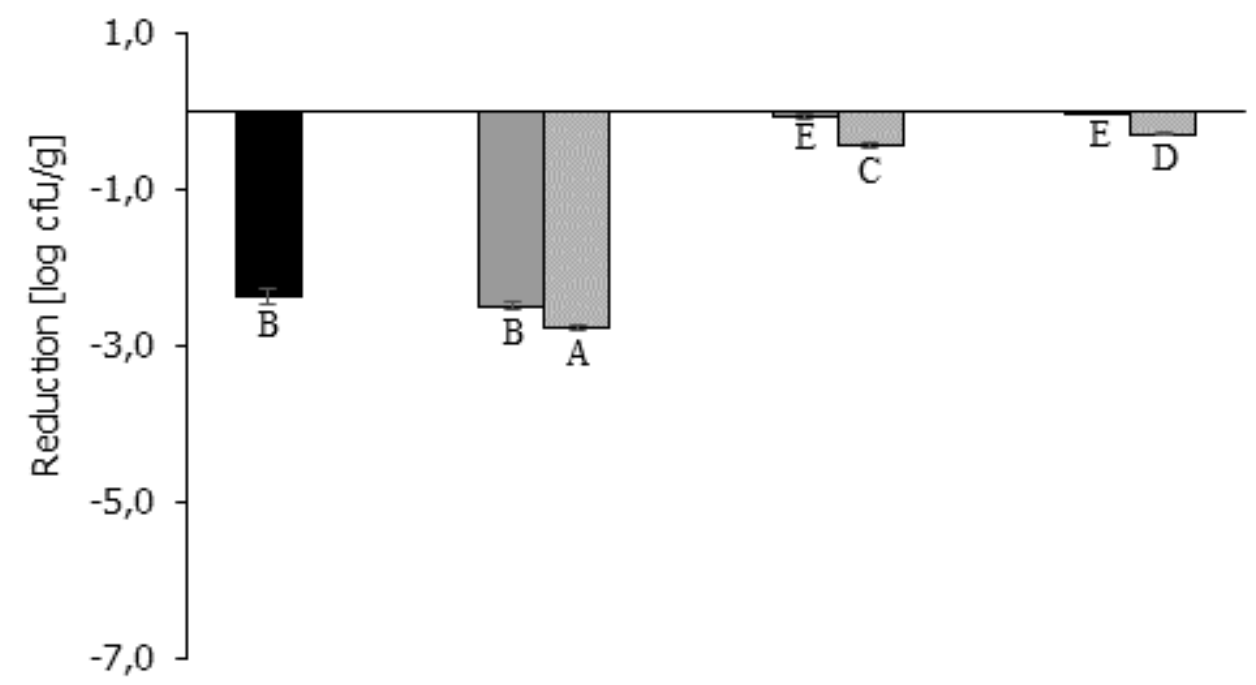

(B)

Temperature $\left[{ }^{\circ} \mathrm{C}\right]$

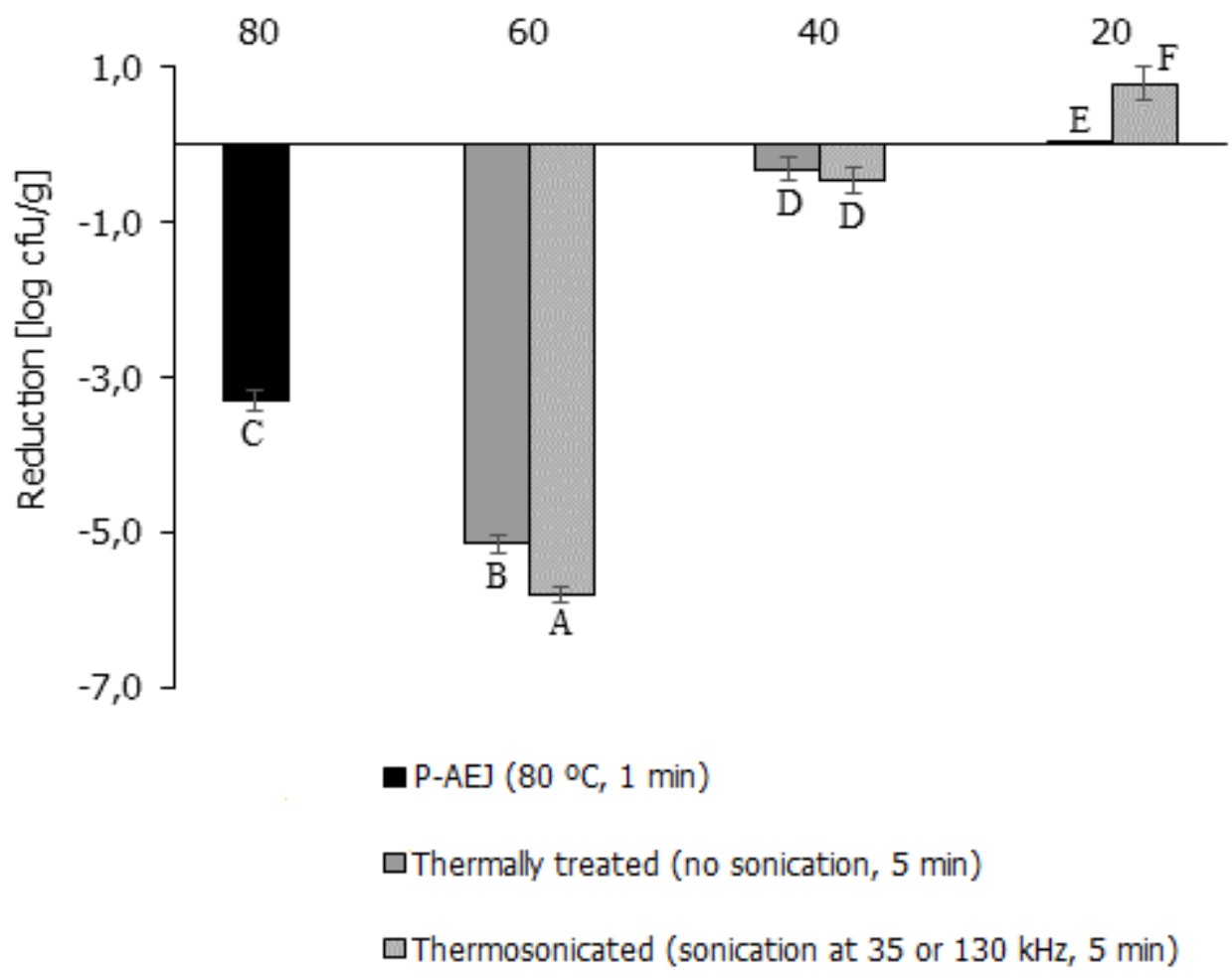

633 
634 Figure 2

(A)

(B)
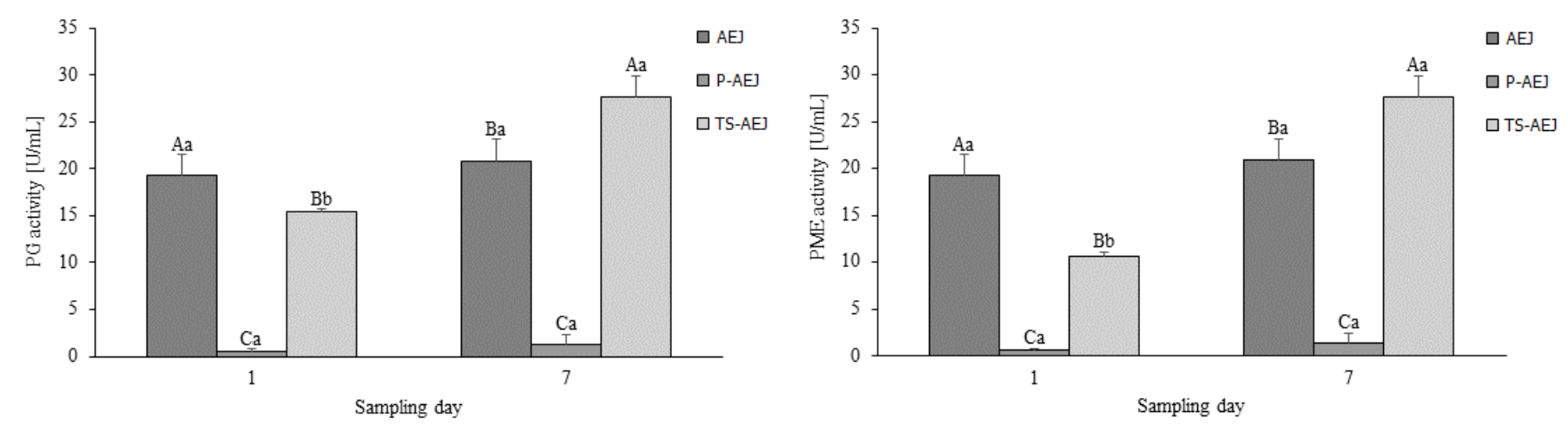
Figure 3

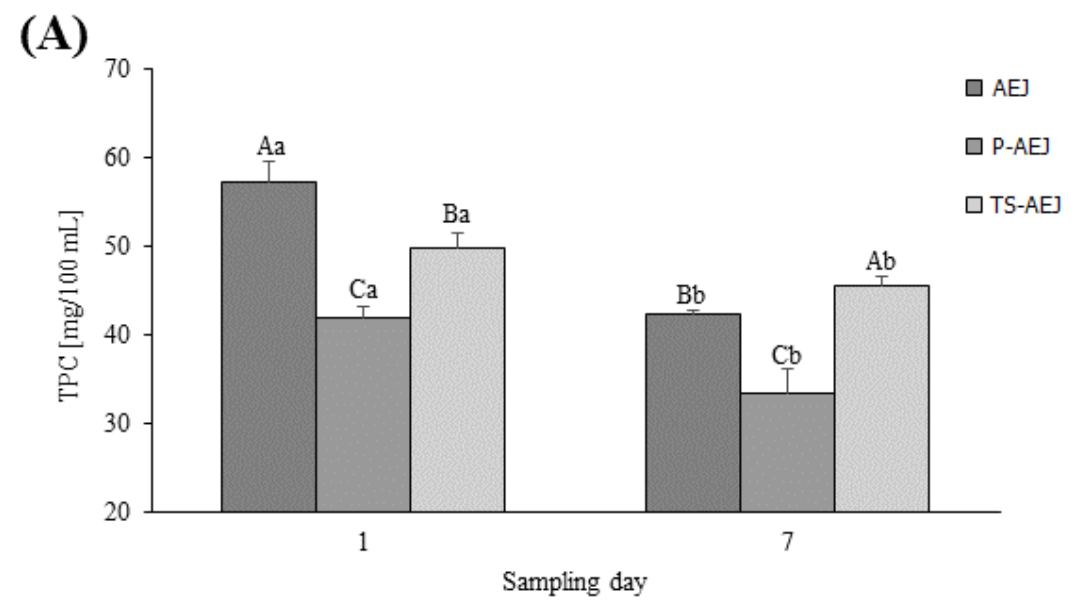

(B)

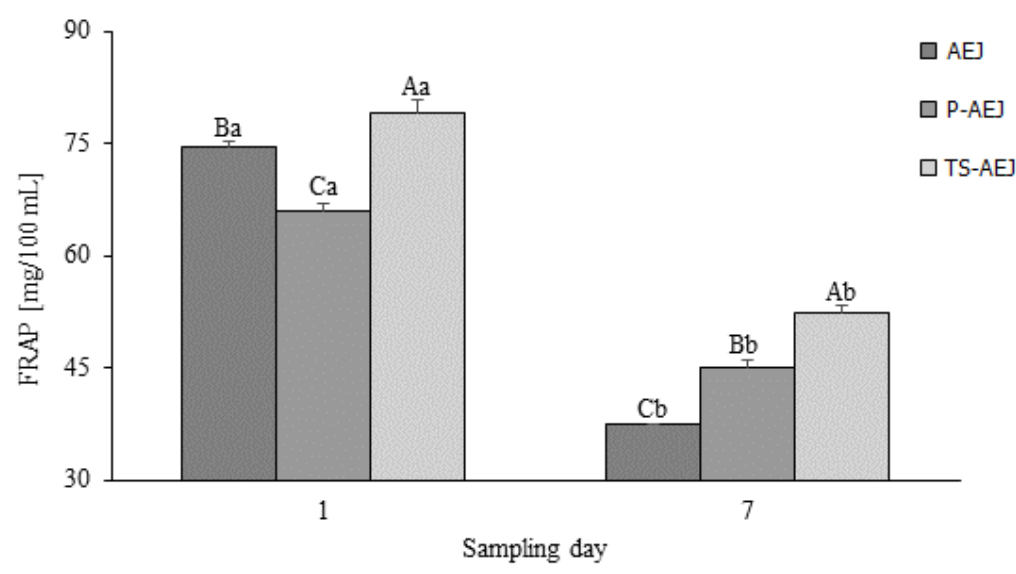

(C)

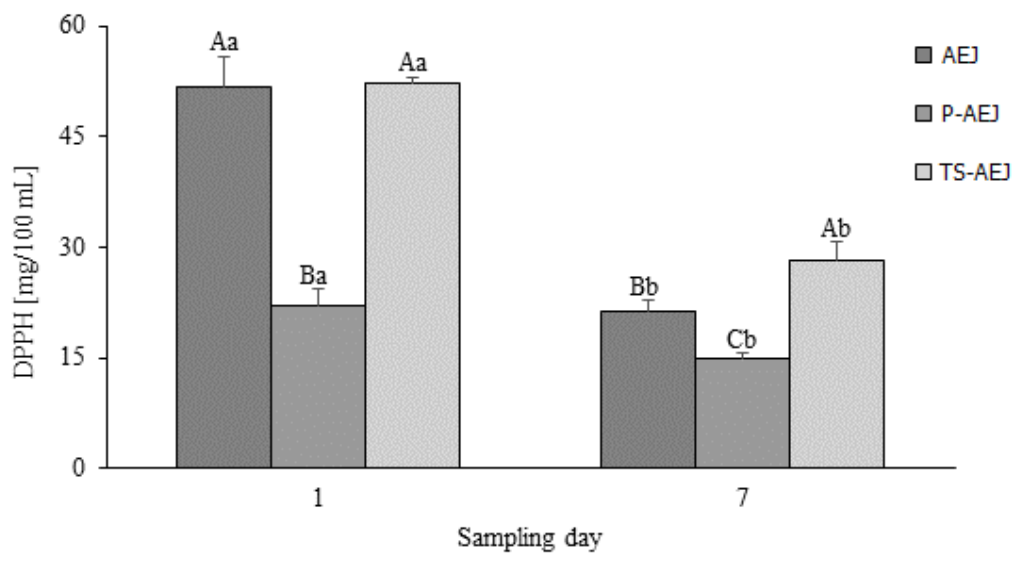


$638 \quad$ Figure 4

(A)

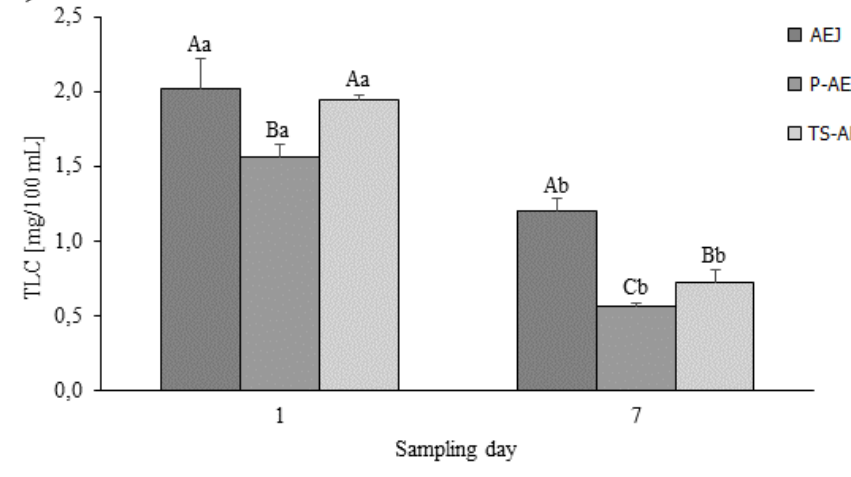

(B)

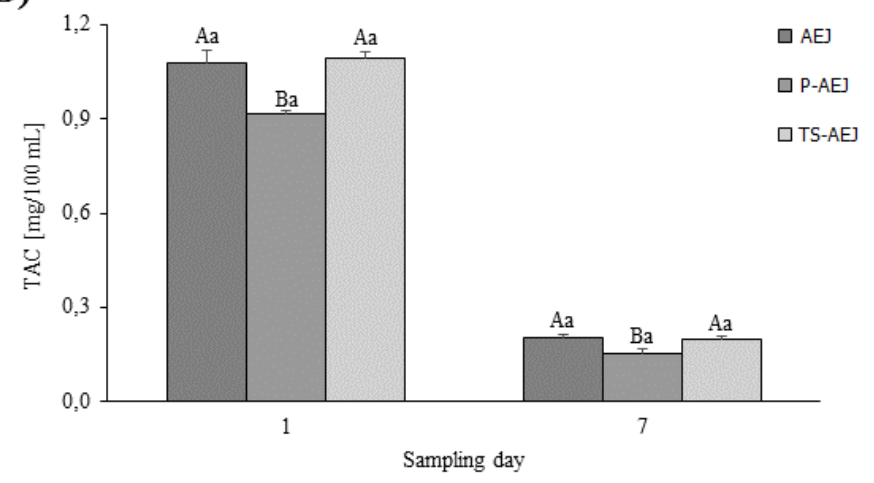


Figure 5

(A)

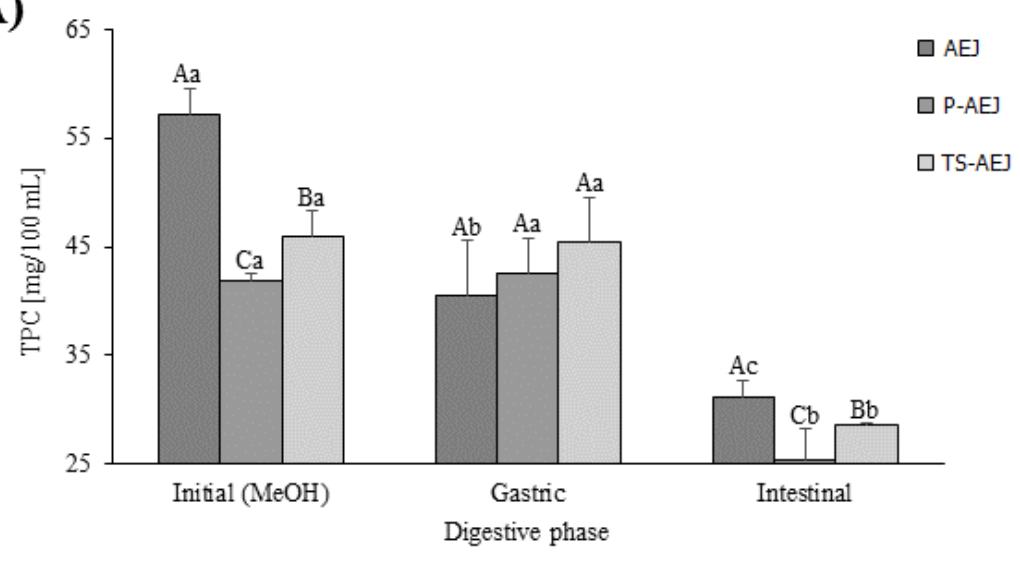

(B)

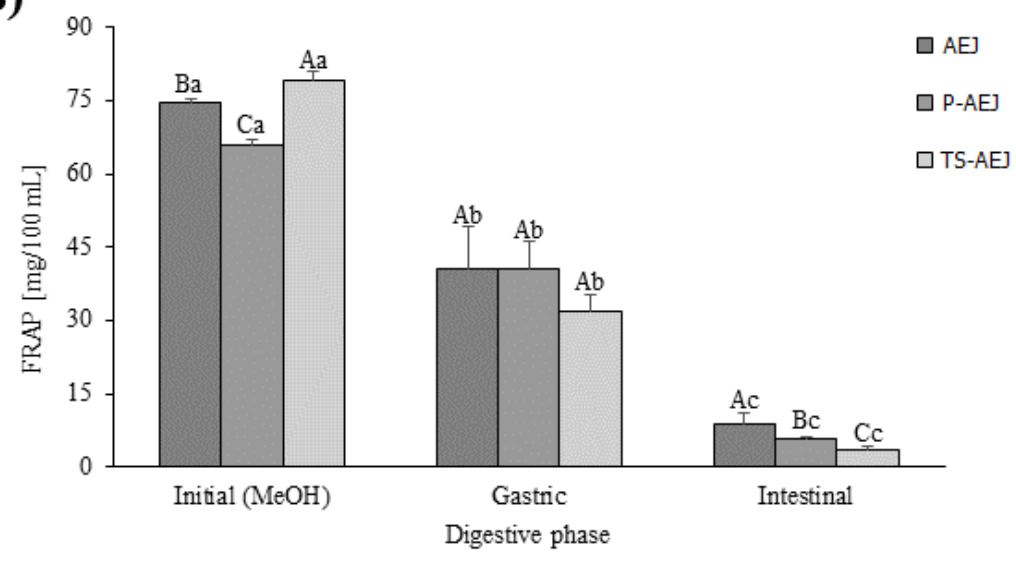

(C)

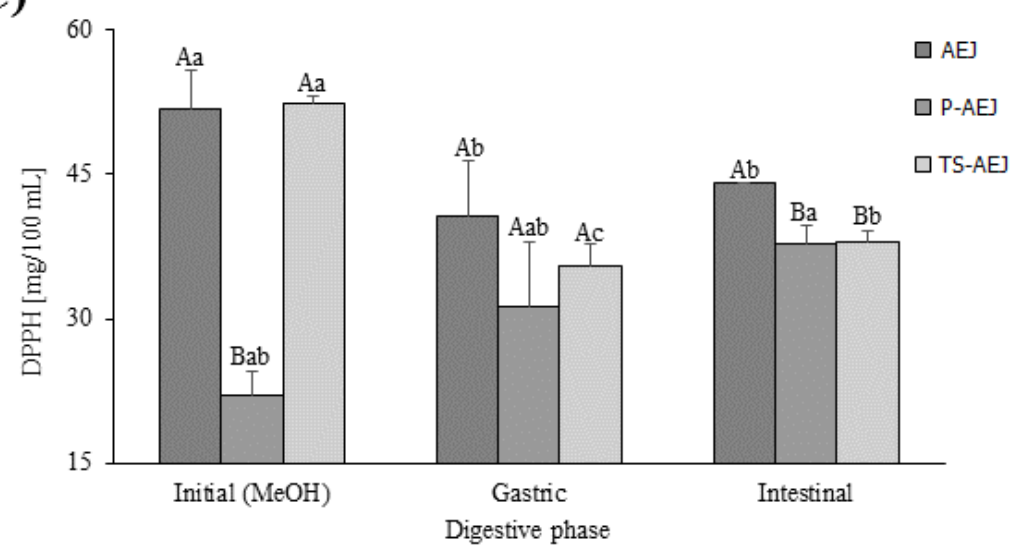

641 
643 enriched tomato juice

\begin{tabular}{|c|c|c|c|c|}
\hline & CJ & AEJ & P-AEJ & TS-AEJ \\
\hline \multicolumn{5}{|l|}{ Day 1} \\
\hline$L^{*}$ & $41.88 \pm 1.06^{\mathrm{D}}$ & $44.79 \pm 0.07^{\mathrm{Ba}}$ & $44.15 \pm 0.33^{\mathrm{Ca}}$ & $45.53 \pm 0.19 \mathrm{Aa}$ \\
\hline$a^{*}$ & $10.91 \pm 0.66^{\mathrm{D}}$ & $13.87 \pm 0.08$ & $12.70 \pm 0.16^{\mathrm{Ca}}$ & $12.94 \pm 0.08 \mathrm{Ba}$ \\
\hline$b^{*}$ & $16.21 \pm 0.83^{\mathrm{A}}$ & $14.50 \pm 0.14^{\mathrm{Ba}}$ & $14.40 \pm 0.24^{\mathrm{Ba}}$ & $14.65 \pm 0.20^{\mathrm{Ba}}$ \\
\hline$C{ }^{*} a b$ & $19.54 \pm 1.05^{\mathrm{A}}$ & $20.06 \pm 0.15^{\mathrm{Aa}}$ & $19.20 \pm 0.26^{\mathrm{Aa}}$ & $19.55 \pm 0.11^{\mathrm{Aa}}$ \\
\hline$\delta \mathbf{E}$ & $4.4 \pm 0.0$ & - & $1.4 \pm 0.3$ & $1.2 \pm 0.1$ \\
\hline pH & $4.25 \pm 0.01^{\mathrm{A}}$ & $3.94 \pm 0.02 \quad \mathrm{Ba}$ & $3.91 \pm 0.02^{\mathrm{Ba}}$ & $3.91 \pm 0.02^{\mathrm{Ba}}$ \\
\hline TTA $(g / L)$ & $3.26 \pm 0.09^{\mathrm{B}}$ & $4.53 \pm 0.44^{\mathrm{Aa}}$ & $4.56 \pm 0.05^{\mathrm{Aa}}$ & $4.70 \pm 0.33^{\mathrm{Aa}}$ \\
\hline SSC ( $\left({ }^{\circ}\right.$ Brix $)$ & $5.03 \pm 0.06^{\mathrm{B}}$ & $6.60 \pm 0.20^{\mathrm{Aa}}$ & $6.67 \pm 0.25^{\mathrm{Aa}}$ & $6.60 \pm 0.30^{\mathrm{Aa}}$ \\
\hline \multicolumn{5}{|l|}{ Day 7} \\
\hline$L^{*}$ & - & $40.90 \pm 0.40^{\mathrm{Bb}}$ & $43.60 \pm 0.16^{\mathrm{Aa}}$ & $41.59 \pm 0.26^{\mathrm{Bb}}$ \\
\hline$a^{*}$ & - & $11.28 \pm 0.07^{\mathrm{Bb}}$ & $12.09 \pm 0.12^{\mathrm{Ab}}$ & $11.36 \pm 0.12^{\mathrm{Ba}}$ \\
\hline$b^{*}$ & - & $11.66 \pm 0.20^{\mathrm{Bb}}$ & $13.53 \pm 0.14^{\mathrm{Ab}}$ & $11.74 \pm 0.08^{\mathrm{Bb}}$ \\
\hline$C * a b$ & - & $16.22 \pm 0.19^{\mathrm{Bb}}$ & $18.15 \pm 0.03^{\mathrm{Ab}}$ & $16.34 \pm 0.13^{\mathrm{Bb}}$ \\
\hline$\delta \mathbf{E}$ & - & - & $3.4 \pm 0.1$ & $0.7 \pm 0.3$ \\
\hline pH & - & $3.92 \pm 0.01 \mathrm{Ba}$ & $3.96 \pm 0.04 \mathrm{Aa}$ & $3.88 \pm 0.03^{\mathrm{Ba}}$ \\
\hline TTA (g/L) & - & $4.26 \pm 0.07^{\mathrm{Ba}}$ & $4.50 \pm 0.47^{\mathrm{ABa}}$ & $4.55 \pm 0.05^{\mathrm{Aa}}$ \\
\hline SSC ( $\left({ }^{\circ}\right.$ Brix $)$ & - & $6.40 \pm 0.10^{\mathrm{Ba}}$ & $6.63 \pm 0.06^{\mathrm{Aa}}$ & $6.67 \pm 0.06^{\mathrm{Aa}}$ \\
\hline
\end{tabular}

644 CJ: Control tomato juice; AEJ: Anthocyanin-enriched juice; P-AEJ: AEJ pasteurised at $64580^{\circ} \mathrm{C}$ for $1 \mathrm{~min}$; TS-AEJ: AEJ thermosonicated at $60{ }^{\circ} \mathrm{C}$ and either 35 or $130 \mathrm{kHz}$ for 5 646 min.

647 Values represent the mean of three independent experiments \pm S.D. Capital letters 648 indicate significant differences between juices at the same sampling day. Lower case 649 letters indicate significant differences between different sampling days for the same juice.

650 The criterion for statistical significance was $p<0.05$. 